\title{
The improvement of an elastic hinge-type torque standard machine in NIMT
}

\author{
Nattapon Saenkhum ${ }^{1}$, Tassanai Sanponpute ${ }^{1}$ \\ ${ }^{1}$ National Institute of Metrology (Thailand), 3/4-5 Moo 3, Klong 5, Klong Luang, Pathumthani 12120, Thailand
}

\begin{abstract}
The National Institute of Metrology of Thailand's (NIMT) strain-controlled elastic hinge-type torque standard machine was designed to cover a measuring range of $1 \mathrm{~N} \cdot \mathrm{m}$ to $1 \mathrm{kN} \cdot \mathrm{m}$. The elastic hinge was used both at the fulcrum and the hanger of the lever arms. The designed elastic hinge's thickness, $0.50 \mathrm{~mm}$, caused a higher stiffness than a sheet metal plate of other types of torque machines. The bending moment of all elastic hinges affected the sum of the torque signal on the lever arm that was used to observe the balancing of the lever. The residual torque sensitivity, which was no better than $0.20 \mathrm{mN} \cdot \mathrm{m}$, significantly affected the uncertainty of the low-range torque realisation.

The calibration and measurement capabilities of the machine were $0.010 \%(k=2)$ in the measurement range of $10 \mathrm{~N} \cdot \mathrm{m}$ to $1 \mathrm{kN} \cdot \mathrm{m}$ and $0.030 \%(k=2)$ in the measurement range of $1 \mathrm{~N} \cdot \mathrm{m}$ to $10 \mathrm{~N} \cdot \mathrm{m}$. In the transducer calibration, the influence of the random bending moment of the elastic hinge affected the repeatability, reproducibility, and linearity of the low torque measurements. The cause of the bending moment of the elastic hinges was a result of the deviation of the centre of gravity (CG) of the weight on the pan from the reference line. To improve CMCs, separate signal calibrations were selected for this experiment i.e. the left hinge, the right hinge, and the fulcrum. The torque in each signal calibration was combined by software and was used to correct the calibration value of the torque.
\end{abstract}

\section{Section: RESEARCH PAPER}

Keywords: Torque standard machine; elastic hinge; torque transducer; bending moment; fulcrum sensitivity

Citation: Nattapon Saenkhum, Tassanai Sanponpute, The improvement of an elastic hinge-type torque standard machine in NIMT, Acta IMEKO, vol. 8, no. 3, article 7, September 2019, identifier: IMEKO-ACTA-08 (2019)-03-07

Editor: Rugkanawan Wongpithayadisai, NIMT, Thailand

Received August 31, 2018; In final form June 6, 2019; Published September 2019

Copyright: This is an open-access article distributed under the terms of the Creative Commons Attribution 3.0 License, which permits unrestricted use, distribution, and reproduction in any medium, provided the original author and source are credited.

Corresponding author: Nattapon Saenkhum, e-mail: nattapon@nimt.or.th

\section{INTRODUCTION}

NIMT's $1 \mathrm{kN} \cdot \mathrm{m}$ elastic hinge-type torque standard machine (TSM) $[1,2,3,4]$ was established in 2004. The machine was designed and assembled by GTM GmbH in Germany. Unfortunately, the left elastic hinge was damaged during the commissioning process at NIMT's Bangkok site. In 2005, the NIMT moved it to a new site in Pathumthani. The machine was reconstructed, including the replacement of the damaged parts and recalibration. The calibration and measurement capabilities (CMCs) were $0.010 \%(k=2)$ in the measurement range of 10 $\mathrm{N} \cdot \mathrm{m}$ to $1 \mathrm{kN} \cdot \mathrm{m}$ and $0.030 \%(k=2)$ in the measurement range of $1 \mathrm{~N} \cdot \mathrm{m}$ to $10 \mathrm{~N} \cdot \mathrm{m}$. The CMCs were proven by the CCM.T$\mathrm{K} 1.2$ comparison in 2008 [5]. The final report was published in 2015.

In 2013, it was found that the machine had problems caused by the residual torque signal from the fulcrum cross-elastic hinge. The problem was resolved by using the displacement sensor to detect the balance position of the lever instead of the damaged elastic hinge. In 2014, the mechanical fulcrum crosselastic hinge completely malfunctioned due to the deformation of its plastic, and this must be replaced. The new fulcrum crosselastic hinge was procured from the manufacturer and was replaced by NIMT staff in the same year. The CMCs were confirmed again by some bilateral comparisons (compared with a PTB certificate and the $10 \mathrm{~N} \cdot \mathrm{m}$ TSM of NIMT $[6,7,8])$. This was our chance to study the strain-controlled elastic hinge characteristic based on each repair and maintenance exercise. The most important point of the machine's realisation was a residual torque that was a dominant uncertainty contribution. NIMT was interested in determining the method of reducing the uncertainty of measurement caused by the residual torque signal. 




Figure 1. Residual torque configuration.

\section{RESIDUAL TORQUE CONFIGURATION}

The original residual torque signal was configured by the manufacturer. The output residual torque signal combined four signals (left hinge, channel 1; right hinge, channel 2 and fulcrum front and rear, channels 3 and 4) by using the electric circuit. The sensitivity of the signals of the left and right hinges was reduced tenfold by using normal resistors with the same resistance on both sides. The reduced signals and the fulcrum signals were combined. The manufacturer aimed to reduce the influence of the left and right elastic hinges signals that would affect the combined signals. The combined signals were converted to a torque unit by an Analogic AN3060 digital weight indicator [9], as shown in Figure 1.

The original residual torque configuration should be realised by the separate signal calibrations as performed in this experiment: left hinge, right hinge, and fulcrum. The residual torque in each signal calibration was combined by software and was used to correct the calibration torque value.

\section{BENDING MOMENT OF ELASTIC HINGE}

\subsection{Asymmetric load}

The imperfection of the manufacturing process of the weight set caused an asymmetric load distribution. Additionally, small steel balls were used to adjust the mass of the weight set. The weight stack on the pan touched the column, and many steel balls inside changed the position independently, as shown in Figure 2. Both of these cases might cause the bending moment at the elastic hinge of lever arm.
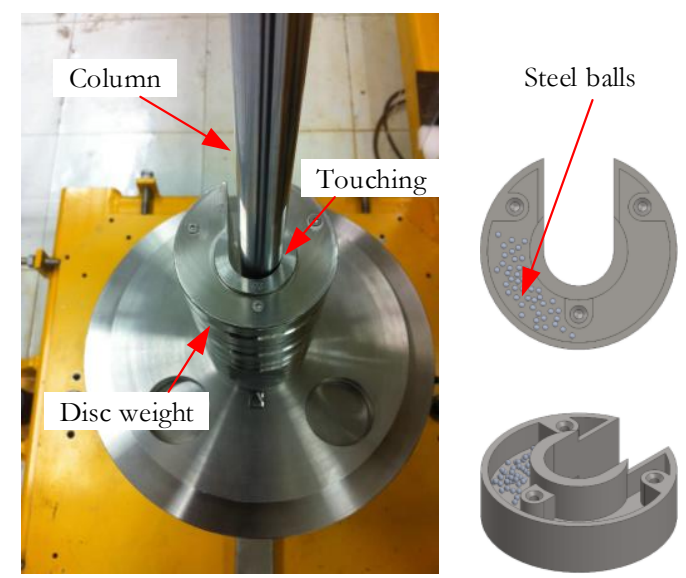

Figure 2. Asymmetric load on the pan due to the imperfection of the manufacturing and the steel balls inside.

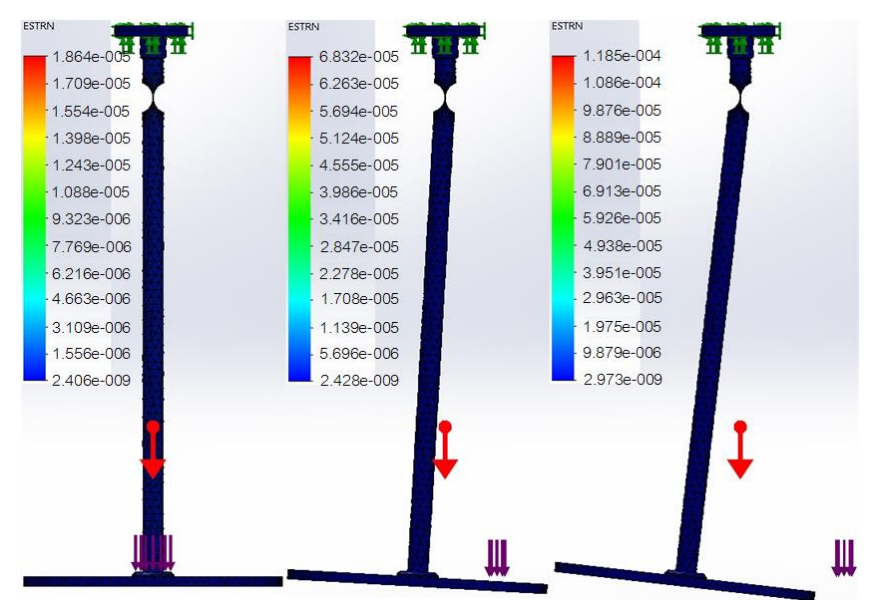

Figure 3. Finite element analysis.

The hypothesis of the asymmetric load was proven by the finite element analysis (FEA) at NIMT. Static analysis was selected for studying the stress, the displacement, and the strain of the elastic hinges. The FEA simulation was designed by applying the $0.5 \mathrm{~N}$ forces on the centre position, at $60 \mathrm{~mm}$ from the centre and $120 \mathrm{~mm}$ from the centre. The elastic hinge geometry was divided into a finite element by a curvature-based mesh algorithm. These small meshes were controlled in the areas in which there is a rapid change in stress, while the large meshes were controlled in the areas in which there was little change in stress [10]. Obviously, the bending value of the elastic hinge depends on the distance of the force on the pan, as shown in Figure 3.

\subsection{The moment of force}

As evident in Figure 4, the centre of the gravitational force acting on the hinge shifted from the original position due to the stacked weights. In this case, the bending moment, $M_{\mathrm{B}}$, was not equal to zero. That variable was effected by the calibration torque, $M_{\mathrm{T}}$, as in Equation (2). The measured bending moment of the elastic hinge should be considered:

$\sum M=0$

$M_{\mathrm{T}}-F_{1} \cdot L_{1}-M_{\mathrm{B}}=0$

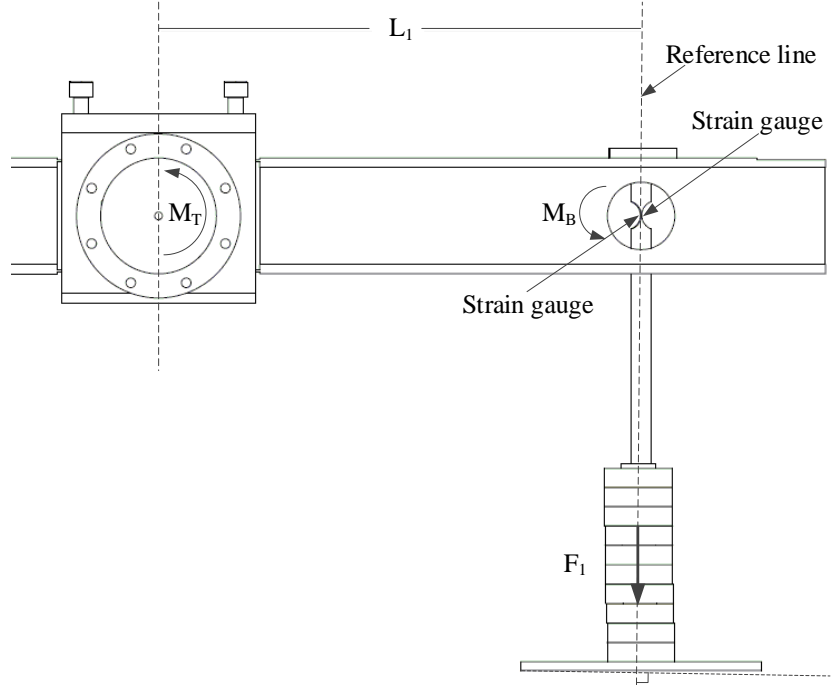

Figure 4. Moment of a force. 

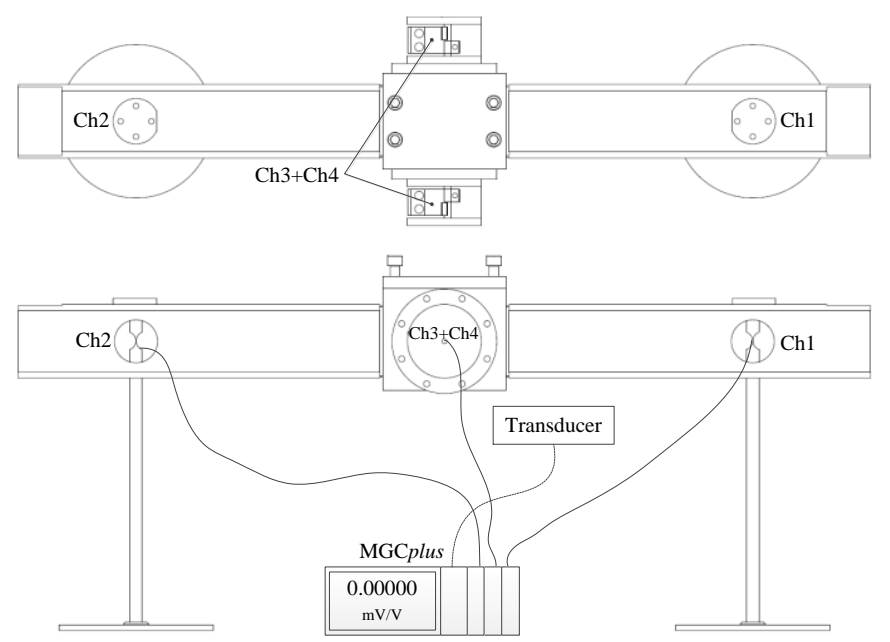

Figure 5. Experiment setup.

$$
M_{\mathrm{B}}=M_{\mathrm{T}}-F_{1} \cdot L_{1}
$$

where:

$F_{1}$ is the force, and
$L_{1}$ is the lever length (approx. $500 \mathrm{~mm}$ ).

\section{EXPERIMENT}

The measured moment of the strain-controlled elastic hinges is realised by considering the signal separation. The indicating device was changed to a four-channel HBM MGCplus synchronised amplifier $(1 \times$ ML38 and $3 \times$ ML30B $)$ [11]. The signal was separated from the combined circuit box to: Ch1; right hinge, $\mathrm{Ch} 2$; left hinge and $\mathrm{Ch} 3+\mathrm{Ch} 4$; fulcrum front and rear. The Ch1, Ch2, Ch3+Ch4, and the transducer were connected to the amplifier, as shown in Figure 5. The transducer did not connect to the TSM. Next, we performed the activities as described in sections 4.1 to 4.4 .

\subsection{Fulcrum cross-elastic hinge realisation}

The fulcrum was preloaded three times at approximately 5 $\mathrm{mN} \cdot \mathrm{m}$. Then, the weight was applied onto the reference position (as shown in Figure 6), as the calibration steps are shown in Figure 7, three times. The weight steps were $50 \mathrm{mg}$, $100 \mathrm{mg}, 200 \mathrm{mg}, 200 \mathrm{mg}$, and $500 \mathrm{mg}$, respectively. The measurement process was done using the left and right pans. In the meantime, the data channel was recorded. Together, the strain signals of clockwise and anticlockwise torque were expressed as a function of the torque by the first-order linear interpolation equation, without the absolute term.

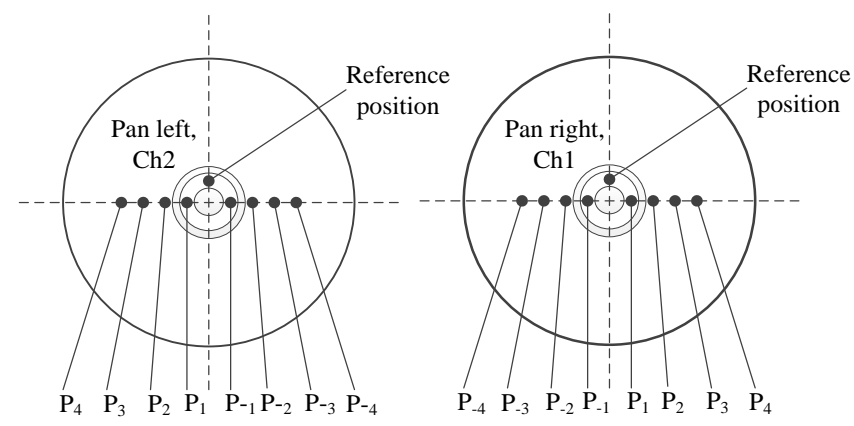

Figure 6. Position of the weight on the pan.
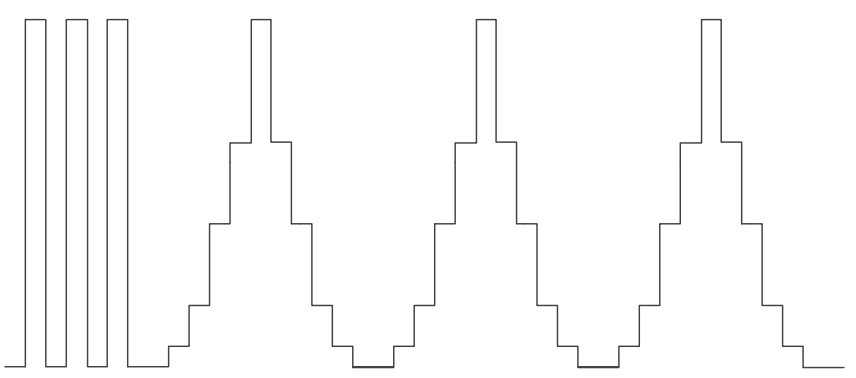

Step: $(50,100,200,200$ and 500) $\mathrm{mg}$

Figure 7. Calibration step.

\subsection{Left and right elastic hinges realisation}

A recognised torque transducer (Rauter; TT1/10 N·m) [12] was used to transfer the torque value to both sides of the elastic hinges. The TT1/10 N.m was calibrated by the $10 \mathrm{~N} \cdot \mathrm{m}$ TSM of NIMT $[6,7]$ in the measurement range of $0.1 \mathrm{~N} \cdot \mathrm{m}$ to $1 \mathrm{~N} \cdot \mathrm{m}$. The repeatability and linearity of the measurement results of TT1 $1 / 10 \mathrm{~N} \cdot \mathrm{m}$ at $0.2 \mathrm{~N} \cdot \mathrm{m}$ were within $0.002 \%$ and $0.004 \%$, respectively. The measurements should be carried out separately for the right and left torques. The next steps were to connect the transducer to the machine, as shown in Figure 8, preload three times at approximately $0.25 \mathrm{~N} \cdot \mathrm{m}$ (50 g weight), and wait for three minutes. Then, we put the same weight on the reference position of the pan and applied the load by using a motor gear until $(0.00000 \pm 0.00010) \mathrm{N} \cdot \mathrm{m}$ of $\mathrm{Ch} 3+\mathrm{Ch} 4$ was indicated. In the meantime, all the channel data was recorded. We performed the same procedure but changed the weight position to $\mathrm{P} 1, \mathrm{P} 2, \mathrm{P} 3, \mathrm{P} 4, \mathrm{P}-1, \mathrm{P}-2, \mathrm{P}-3$, and $\mathrm{P}-4$, as shown in Figure 6 . The interval of the positions was set to $30 \mathrm{~mm}$. The whole process was repeated three times. The first order of the linear interpolation equation was selected to transform the strain signal to express it as a function of the torque.

\subsection{The difference in arm length evaluation}

The difference in arm length between the left and right arms was evaluated by a moment balancing method $[6,7,13]$. This method was implemented by loading the weight on both the left and right pans simultaneously in three ranges: $2 \mathrm{~N}$ to 20 $\mathrm{N}$ (step $2 \mathrm{~N}, 4 \mathrm{~N}, 8 \mathrm{~N}, 12 \mathrm{~N}, 16 \mathrm{~N}, 20 \mathrm{~N}$ ), $20 \mathrm{~N}$ to $100 \mathrm{~N}$ (step $20 \mathrm{~N}, 40 \mathrm{~N}, 60 \mathrm{~N}, 80, \mathrm{~N} 100 \mathrm{~N}$ ), and $100 \mathrm{~N}$ to $1,000 \mathrm{~N}$ (step $100 \mathrm{~N}, 200 \mathrm{~N}, 400 \mathrm{~N}, 600 \mathrm{~N}, 800 \mathrm{~N}, 1,000 \mathrm{~N}$ ), as shown in

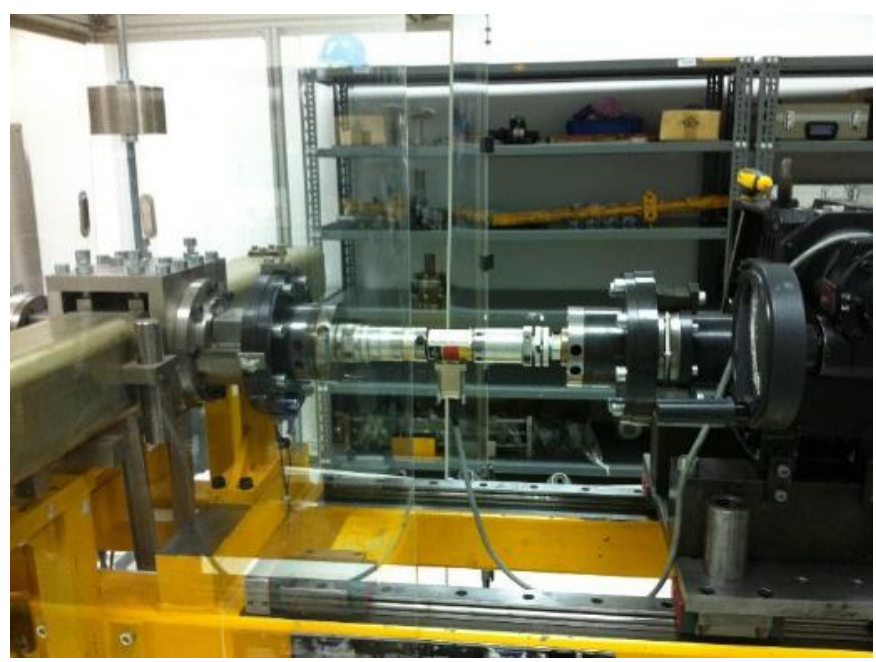

Figure 8. Transducer setup. 


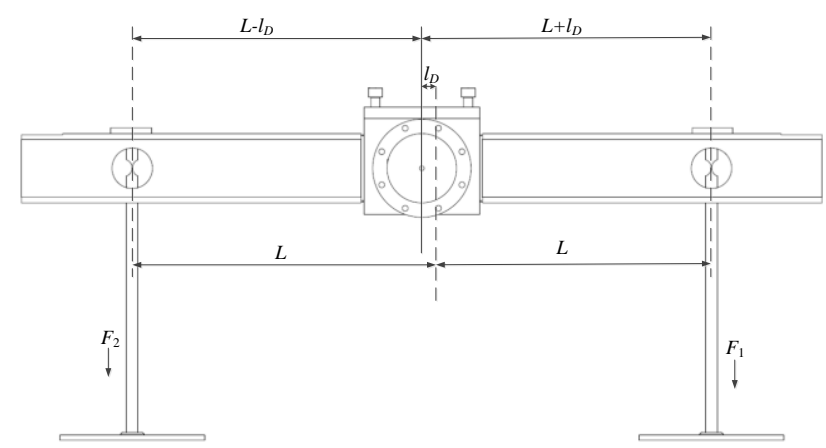

Figure 9. Difference in arm length between the left and right arms.

Figure 9. The measurement in each range must be done for three cycles. If the system is in equilibrium, the clockwise torques, $M_{1}$ and anti-clockwise torque, $M_{2}$ shall be equal. The difference in arm length, $l_{D}$, was calculated by Equations (4) to (9).

$M_{1}=M_{2}$

$F_{1} \cdot\left(L-l_{\mathrm{D}}\right)=F_{2} \cdot\left(L+l_{\mathrm{D}}\right)$

$F_{1} \cdot L-F_{1} \cdot l_{\mathrm{D}}=F_{2} \cdot L+F_{2} \cdot l_{\mathrm{D}}$

$F_{1} \cdot L-F_{2} \cdot L=F_{1} \cdot l_{D}+F_{2} \cdot l_{D}$

$F_{1} \cdot L-F_{2} \cdot L=l_{\mathrm{D}} \cdot\left(F_{1}+F_{2}\right)$

$l_{D}=\left(\frac{F_{1} \cdot L-F_{2} \cdot L}{F_{1}+F_{2}}\right)$

\subsection{Torque transducer calibration}

The realised residual torque from Ch1, Ch2, and Ch3+Ch4 was combined by a software program (shown in Figure 10) used to monitor and correct the calibration torque value in the calibration process. The proposed method was proven reliable by comparing the transducer calibration results characteristics: the repeatability, reproducibility, and linearity of the measurement according to the German Industrial Standard documentation DIN 51309 [14].

\section{EXPERIMENTAL RESULTS}

\subsection{Fulcrum cross-elastic hinge realisation results}

Two cross elastic hinges' signals at the fulcrum $(\mathrm{Ch} 3+\mathrm{Ch} 4)$ were expressed as a function of torque by using the first order of the interpolation equation without the absolute term, as

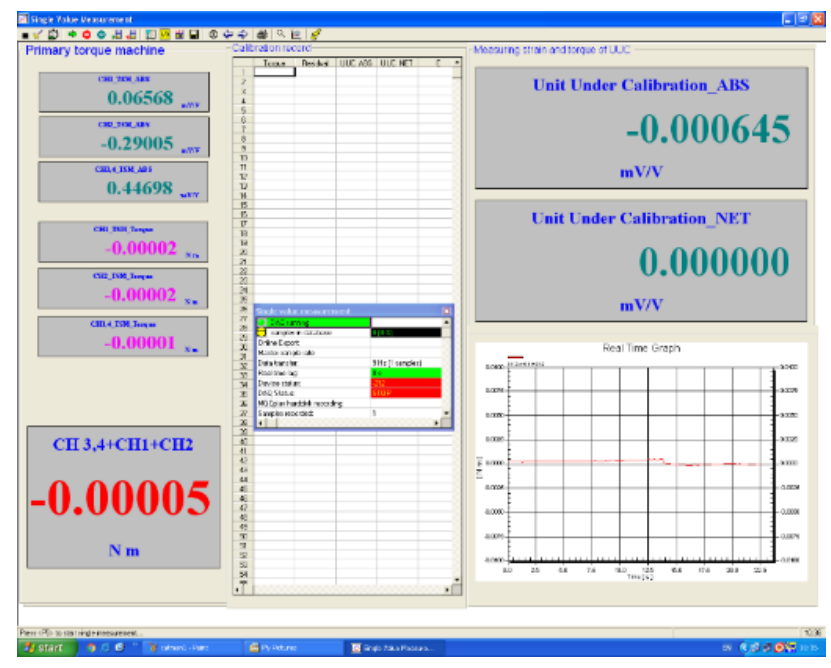

Figure 10. Software program.

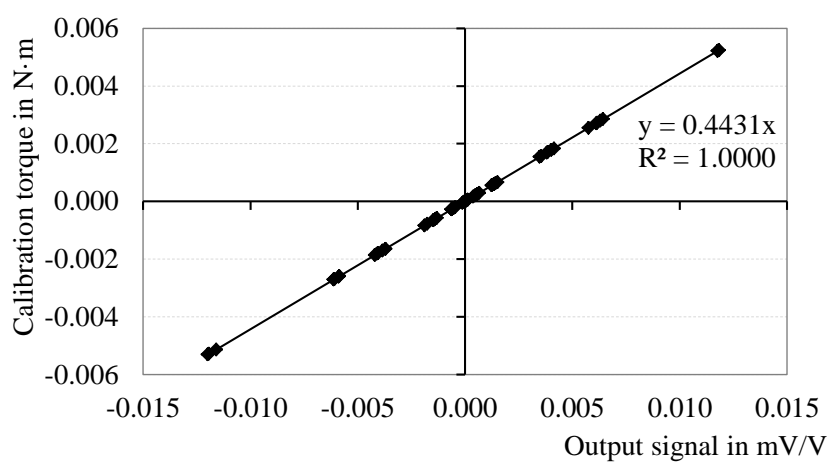

Figure 11. Linear regression of the $\mathrm{Ch} 3+\mathrm{Ch} 4$ signal.

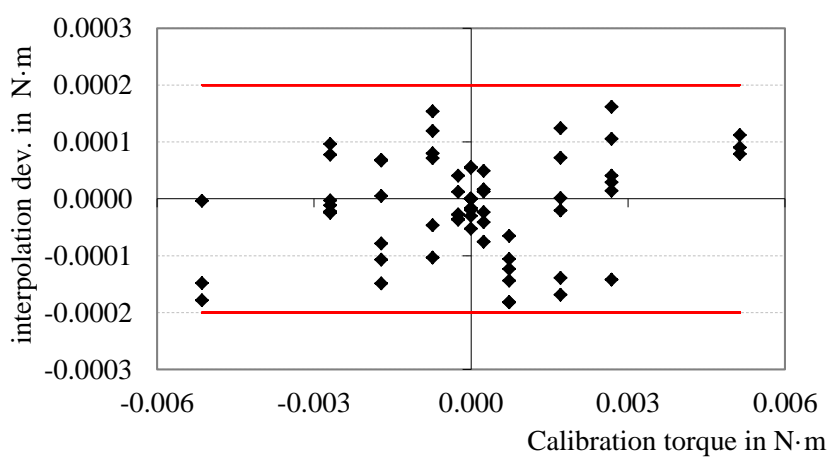

Figure 12. Interpolation deviation.

shown in Figure 11. The interpolation deviation results were within $\pm 0.0002 \mathrm{~N} \cdot \mathrm{m}$, as shown in Figure 12. That was a limitation of the fulcrum sensitivity of the machine, which was due to the designed elastic hinge's thickness, $0.50 \mathrm{~mm}$, causing a higher stiffness compared to the sheet metal plate of the other types of TSMs.

\subsection{Left and right elastic hinges realisation results}

The calibration results for the bending moment of the elastic hinge are shown in Table 1 and Table 2. It is clear that the torque calibration in which the weight was not put on the pan did not change. That meant the moment of the hinge was zero. The weight placed at each position on the pan from the reference line in any direction caused a varied torque vector, as shown in Figure 13. It was therefore possible to determine the sensitivity, as shown in Figure 14. It was found that the sensitivities of the left and right elastic hinges were different.

Table 1. Ch1; Clockwise torque measurement results.

\begin{tabular}{c|r|r|r|r|r}
\hline \multicolumn{2}{c|}{\begin{tabular}{c} 
Mass position \\
\multicolumn{2}{c|}{ in $\mathrm{m}$}
\end{tabular}} & $\begin{array}{c}\text { Transducer } \\
\text { in N·m }\end{array}$ & \multicolumn{2}{c|}{ Ch3+Ch4 } & \multicolumn{2}{c}{ Output signal in $\mathrm{NV} \cdot \mathrm{m}$} & \multicolumn{1}{c}{ Ch1 } & Ch2 \\
\hline$P_{-4}$ & -0.12 & 0.24037 & -0.00003 & 0.11646 & 0.00010 \\
\hline$P_{-3}$ & -0.09 & 0.24269 & -0.00004 & 0.08790 & 0.00008 \\
\hline$P_{-2}$ & -0.06 & 0.24500 & -0.00006 & 0.05934 & 0.00005 \\
\hline$P_{-1}$ & -0.03 & 0.24748 & -0.00005 & 0.02929 & 0.00009 \\
\hline Ref. & 0 & 0.24996 & -0.00005 & -0.00077 & 0.00013 \\
\hline$P_{1}$ & 0.03 & 0.25220 & -0.00004 & -0.02797 & 0.00014 \\
\hline$P_{2}$ & 0.06 & 0.25444 & -0.00004 & -0.05517 & 0.00014 \\
\hline$P_{3}$ & 0.09 & 0.25680 & -0.00001 & -0.08353 & 0.00011 \\
\hline$P_{4}$ & 0.12 & 0.25917 & 0.00002 & -0.11189 & 0.00008 \\
\hline & & & & &
\end{tabular}


Table 2. Ch2; Anti-clockwise torque measurement results.

\begin{tabular}{c|r|r|r|r|r}
\hline \multicolumn{2}{c|}{$\begin{array}{c}\text { Mass position } \\
\text { in } \mathrm{m}\end{array}$} & Transducer & Ch3+Ch4 & \multicolumn{2}{c}{ Output signal in $\mathrm{mV} / \mathrm{V}$} \\
in N.m & in N.m & Ch1 & \multicolumn{1}{c}{ Ch2 } \\
\hline $\mathrm{P}_{-4}$ & -0.12 & -0.24009 & -0.00001 & 0.00019 & -0.11620 \\
\hline $\mathrm{P}_{-3}$ & -0.09 & -0.24257 & 0.00002 & 0.00018 & -0.08699 \\
\hline $\mathrm{P}_{-2}$ & -0.06 & -0.24504 & 0.00006 & 0.00006 & -0.05779 \\
\hline $\mathrm{P}_{-1}$ & -0.03 & -0.24750 & 0.00004 & 0.00015 & -0.02902 \\
\hline Ref. & 0 & -0.24995 & 0.00003 & 0.00018 & -0.00025 \\
\hline $\mathrm{P}_{1}$ & 0.03 & -0.25233 & 0.00000 & 0.00019 & 0.02776 \\
\hline $\mathrm{P}_{2}$ & 0.06 & -0.25470 & -0.00002 & 0.00016 & 0.05576 \\
\hline $\mathrm{P}_{3}$ & 0.09 & -0.25721 & 0.00001 & -0.00004 & 0.08557 \\
\hline $\mathrm{P}_{4}$ & 0.12 & -0.25973 & 0.00003 & -0.00018 & 0.11537 \\
\hline
\end{tabular}

The residual torque of the machine, $M_{\mathrm{R}}$, was calculated by a summation of the torque vector signals at the fulcrum (Ch3+Ch4), a bending moment of the right elastic hinge (Ch1), and a bending moment of the left (Ch2). The calibration torque, $M_{\mathrm{T}}$, was calculated by a summation of the torque vectors, including the generated torque $\left(F_{1} \cdot L_{1}\right)$ and the residual torque value $M_{\mathrm{R}}$.

\subsection{Difference in arm length evaluation results}

The difference in the arm length between the left and right arms varied between $23 \mu \mathrm{m}$ and $33 \mu \mathrm{m}$, as shown in Figure 15 . The difference in the lever arm length in each couple force step was expressed as a function of length by a third order interpolation equation, including the absolute term. The difference in arm length must be used to correct the effective lever arm length, $L_{1}$, for each calibration torque value. The shift in the difference of arm length had a direct effect on the linearity of the calibration. The difference in the arm length, $l_{\mathrm{Di}}$ (in micrometres), of each calibration torque step, $M_{\mathrm{Ti}}$, was calculated by Equation (10).

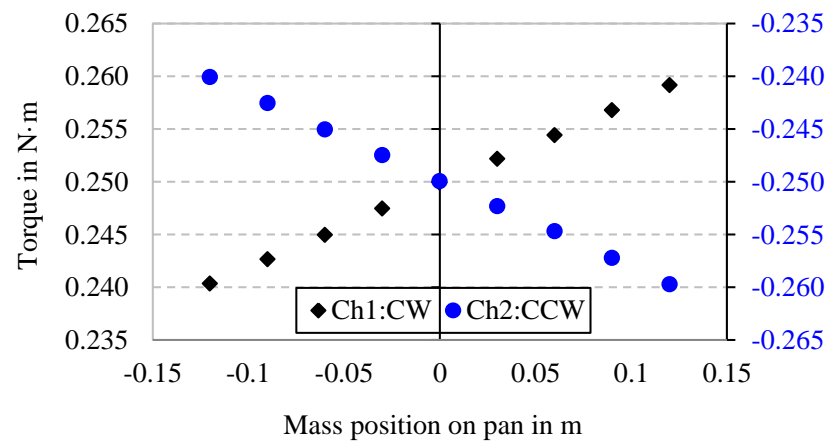

Figure 13. Varied torque by mass position.

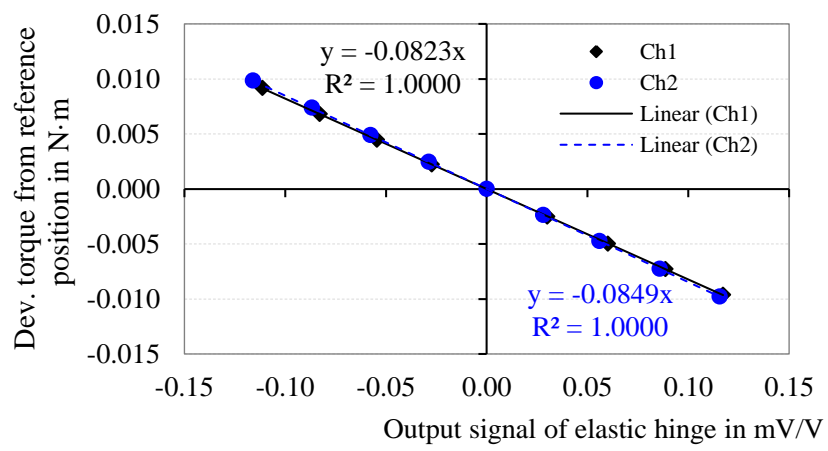

Figure 14. Linear regression of the Ch1 and Ch2 signals.

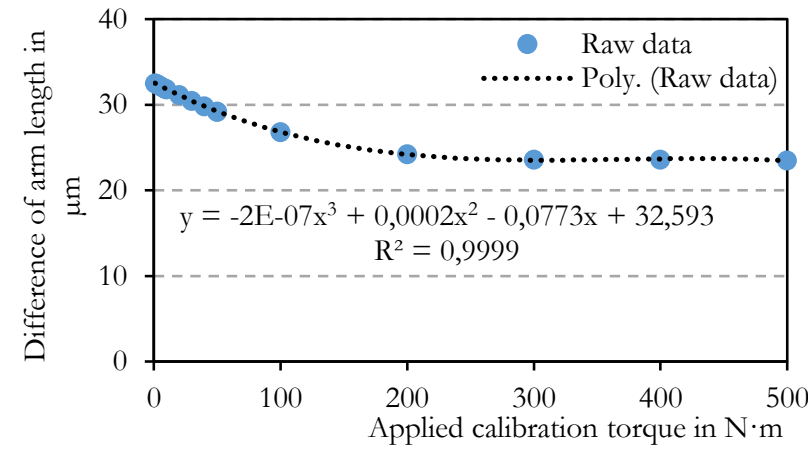

Figure 15. Change in the difference in arm length.

$$
l_{D_{i}}=-0.0000007 M_{i}^{3}+0.0002 M_{i}^{2}-0.0773 M_{i}+32.593
$$

The influence of the variation in the difference in arm length $(10 \mu \mathrm{m})$ affected the linearity of the measurement by about 2 ppm relative to the lever arm of $500 \mathrm{~mm}$ and affected the certified output signals of the transducer under calibration by about $7 \mathrm{ppm}$. However, the difference in arm length of each calibration torque step was used to calculate the effective lever arm length, $L_{1 \mathrm{i}}$, by summing it with half of the entire measured lever length. The uncertainty in the different length evaluation and entire lever length measurement must be taken into account.

\subsection{The comparison results of the torque transducer calibration characteristics}

The calibration torque, $M_{\mathrm{T}}$, was corrected by the residual torque value and the difference in arm length of both configurations (original and this research's concepts). However, the original configuration of the residual torque did not concern the bending moment from the asymmetrical load. The measurement results for the torque transducer calibration were interpolated to the nominal torque value. The comparison results for the repeatability, reproducibility, and linearity characteristics are shown in Figure 16, Figure 17 and Figure 18, respectively. Those results were a calibration of the same transducer, but different configurations for the residual torque signal. The random bending moment affected the repeatability, reproducibility, and linearity of measurement.

It was found from the experiment that the residual torque combined with the bending moment could be used to correct the calibration torque value, because the actual residual torque sensitivity was calibrated. Considering the above three parameters, this research proposed a method of significantly improving the torque calibration's characteristics.

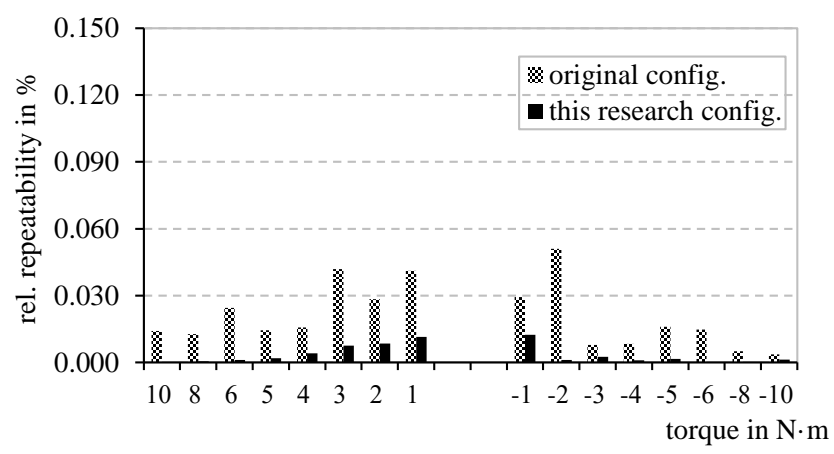

Figure 16. The repeatability characteristic. 


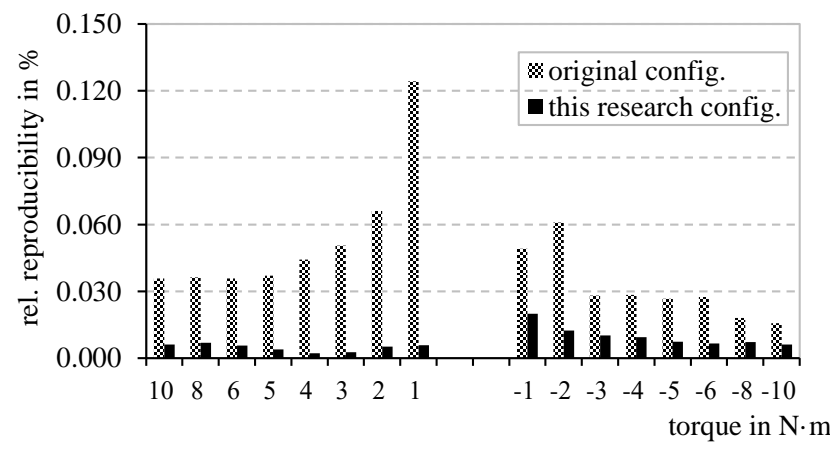

Figure 17. The reproducibility characteristic.

\section{CONCLUSIONS}

The bending moments of the right and left elastic hinges were the results of the force-applied position that deviated from the reference line. The cause of the misposition of the applied force was a result of an imperfection in the manufacturer's process and a small steel ball inside the weight.

The proposed method in this research can resolve the undesirable influence of the bending moment of elastic hinges by significantly improving the repeatability, reproducibility, and linearity of the measurement. In the future, the problem with the asymmetric load should be corrected by the fabrication of new standard weights.

The holder of the strain controlled elastic hinge type torque standard machine should be considered the influence of the bending moment, which affected the uncertainty of the measurement in a low torque calibration, especially when it was lower than $1.0 \%$ of the maximum capacity of the machine.

The calibration and measurement capabilities (CMCs) was still maintained at $0.030 \%(k=2)$ at the measurement range 1 $\mathrm{N} \cdot \mathrm{m}$ to $10 \mathrm{~N} \cdot \mathrm{m}$. However, the CMCs at the measurement range $2 \mathrm{~N} \cdot \mathrm{m}$ to $10 \mathrm{~N} \cdot \mathrm{m}$ was improved to $0.020 \%(k=2)$.

\section{REFERENCES}

[1] H. Gassmann, T. Allgeier, U. Kolwinski, A new design of primary torque standard machines, Proc. of the XVI IMEKO World Congress, Vienna, Austria, 25-28 September 2000.

[2] R. Oliveira, L. Cabral, U. Kolwinski, D. Schwind, Performance of the new primary torque standard machine of INMETRO, Brazil, Proc. of IMEKO TC3 "Force, Mass and Torque Measurements", Cairo, Egypt, 19-23 February 2005.

[3] H. W. Werner, D. Schwind, $25 \mathrm{kN} \cdot \mathrm{m}$ torque calibration machine reaches $U_{\mathrm{bmc}}=0.008 \%$ using new design features, Proc. of the XVIII IMEKO World Congress, Rio de Janeiro, Brazil, 17-22 September 2006.

[4] T. Allgeier, U. Kolwinski, D. Schwind, Jockey-weight lever machines for force and torque, Proc. of the Joint International Conference on "Force, Mass, Torque, Hardness, and Civil

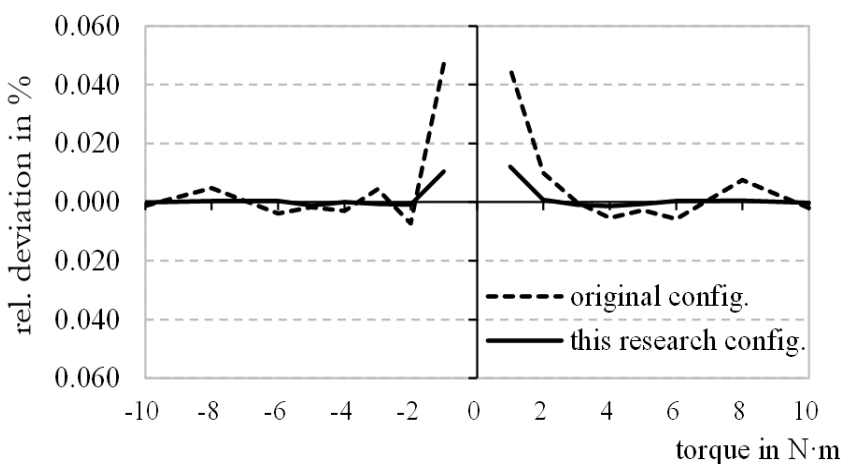

Figure 18. The relative interpolation deviation of results.

Engineering Metrology in the Age of Globalization", Celle, Germany, 24-26 September 2002.

[5] D. Röske, Final report on the torque key comparison CCM.TK1.2 measurand torque: $0 \mathrm{~N} \cdot \mathrm{m}, 500 \mathrm{~N} \cdot \mathrm{m}, 1000 \mathrm{~N} \cdot \mathrm{m}$, Metrologia 52 (2015) Tech. Suppl. Online [Accessed 31 August 2018] https://kcdb.bipm.org/appendixB/appbresults/ccm.t-k1/ccm.tk1.2.pdf

[6] T. Sanponpute, P. Chantaraksa, N. Saenkhum, N. Arksonnarong, Suspended-fulcrum torque standard machine, Proc. of the XIX IMEKO World Congress "Fundamental and Applied Metrology", Lisbon, Portugal, 6-11 September 2009.

[7] T. Sanponpute, N. Arksonnarong, A. Brüge, N. Saenkhum, Suspended-fulcrum torque standard machine, $2^{\text {nd }}$ report, Proc. of the XXI IMEKO World Congress, Prague, Czech Republic, 30 August - 4 September 2015.

[8] A. Nishino, K. Ogushi, T. Sanponpute, N. Arksonnarong, Interlaboratories comparison between NMIJ and NIMT for calibration capability of a low nominal capacity torque measuring device in the range from $0.1 \mathrm{~N} \cdot \mathrm{m}$ to $1 \mathrm{~N} \cdot \mathrm{m}$, SICE 2016, Tsukuba, Japan, 20-23 September 2016.

[9] Analogic: The World Resource for Precision Signal Technology, AN3060 Digital Weight Indicator User Manual, Analogic Corporation, MA 01960-7987, USA, P/N 82-5111 Rev.3.

[10] SolidWorks Corporation, Solidworks Simulation, Dassault Systemes SolidWorks Corporation, MA 02451, USA, PMT1540ENG.

[11] HBM, Operating manual amplifier system MGCplus with display and control panel AB22A/AB32, Hottinger Baldwin Messtechnik GmbH, Darmstadt, Germany, B0534-14.1 en.

[12] N. Saenkhum, T. Sanponpute, The optimization of continuous torque calibration procedure, Measurement 107 (2017) pp. 172178.

[13] N. Arksonnarong, N. Saenkhum, P. Chantaraksa, C. Schlegel, T. Sanponpute, $5 \mathrm{kN} \cdot \mathrm{m}$ torque standard machine of NIMT, Proc. of the Asia-Pacific Symposium on Measurement of Mass, Force \& Torque (APMF 2017), Krabi, Thailand, 19-23 November 2017.

[14] DIN 51309, Materials testing machines - Calibration of static torque measuring devices, Deutsches Institut für Normung e. V., Rev. 05, 2005-12-01. 